\title{
Full title: Is "inconsistency" in Research Ethics Committee decision-making really a problem? An empirical investigation and reflection
}

\section{Short title: Is "Inconsistency" in Research Ethics Committees really a problem?}

E.L. Angell ${ }^{1}$, C.J. Jackson ${ }^{2}$, R.E. Ashcroft ${ }^{3}$, A. Bryman ${ }^{4}$, K. Windridge, ${ }^{5}$ M. Dixon-Woods ${ }^{6}$

1. Research Associate, Social Science Group, Department of Health Sciences, $2^{\text {nd }}$ Floor, Adrian Building, University of Leicester, Leicester LE1 7RH, UK

2. Research Associate, Social Science Group, Department of Health Sciences, $2^{\text {nd }}$ Floor, Adrian Building, University of Leicester, Leicester LE1 7RH, UK

3. Professor of Biomedical Ethics, Institute of Health Sciences Education, Queen Mary University of London, Barts and the London Medical School, 40 New Road, London E1 2AX

4. Professor of Organisational and Social Research, Management Centre, Ken Edwards Building, University of Leicester, University Road, Leicester LE1 7RH, UK.

5. Research Fellow, Trent Research and Development Support Unit, Department of Health Sciences, University of Leicester, 22-28 Princess Road West, Leicester LE1 6TP, UK

6. Corresponding author:

Dr Mary Dixon-Woods

Reader in Social Science and Health

Social Science Group, Department of Health Sciences

$2^{\text {nd }}$ Floor, Adrian Building

University of Leicester

Leicester LE1 7RH

Tel: 01162297262

Fax: 01162292750

Email: md11@le.ac.uk

Word count:

Key words: Research ethics committees; research governance; research proposals; ethical dilemmas; qualitative 


\section{Abstract}

Research Ethics Committees (RECs) are frequently a focus of complaints from researchers, but evidence about the operation and decisions of RECs tends to be anecdotal. We conducted a systematic study to identify and compare the ethical issues raised in 54 letters to researchers about the same 18 applications submitted to three RECs over one year. The most common type of ethical trouble identified in REC letters related to informed consent, followed by scientific design and conduct, care and protection of research participants, confidentiality, recruitment and documentation. Community considerations were least frequently raised. There was evidence of variability in the ethical troubles identified and the remedies recommended. This analysis suggests that some principles may be more institutionalised than others, and offers some evidence of inconsistency between RECs. Inconsistency is often treated as evidence of incompetence and caprice, but a more sophisticated understanding of the role of RECs and their functioning is required. 


\section{Introduction}

Research Ethics Committees (RECs), have an important role in the regulation of research involving humans. ${ }^{1}$ The importance of systematic and consistent decision-making by RECs has been repeatedly emphasised. ${ }^{2}{ }^{3}$ However, most current evidence about the operation and functioning of RECs is anecdotal. It is often in the form of reports from frustrated researchers about single applications, ${ }^{45}$ and sometimes derives from wounding encounters. Systematic evidence about the normal processes of how RECs operate is needed. ${ }^{6}$ In this paper we report an analysis of letters written by RECs to researchers about a range of different types of application as part of a controlled study.

Letters to researchers in response to applications state the reasons that RECs give to support the decisions they make, and are a key source of information about what RECs see as decisive and persuasive in their decision processes. Although RECs may reach decisions "backstage" ${ }^{7}$ on a wide variety of grounds, in letters in the UK they are formally required to give reasons in line with published guidance, known as GAfREC (Governance Arrangements for Research Ethics Committees). We aimed to identify what kinds of issues are raised as ethical troubles by RECs in letters to researchers, and to assess how far the kinds of ethical issues raised and remedies proposed were similar between different committees in response to the same applications.

\section{Methods}

\section{Data sources}

The three RECs in one Strategic Health Authority in the UK participated in our project, which ran between February 2004 and February 2005. The members of the three RECs in the project agreed to review an additional application at each of the meetings during the period of the study. All applications used in our study were selected from those routinely submitted to the RECs, and were therefore "genuine" and not constructed for purposes of the project. For each application in the project, each of the three RECs gave full consideration to the application and wrote a decision letter as part of the routine work of the committee. However, each application was assigned (by EA, who was a REC administrator at the time of the study) a "lead" committee in advance of the meetings where the application was to be considered; the decision letter to the applicants was issued from the lead committee only, so that applicants received only one decision letter. Committee members received all applications for each meeting as a package, and 
were not told which application was a "study" application, nor were they told whether they were the "lead" committee for any particular application.

Purposive sampling was used to select different types of applications, including different study types. Each of the 18 applications in our project (seven qualitative, six non-intervention, and five intervention) was reviewed independently by all three RECs. Each REC reviewed six applications as the "lead" and a further 12 applications as a non-lead.

The Central Office for Research Ethics Committees confirmed that the project constituted service evaluation and need not be reviewed by a Research Ethics Committee. Members of the RECs in the project gave verbal consent to participation in Autumn 2003. Researchers whose applications were included were contacted following the decision letter from the lead REC. They were given an explanation of the project, advised that the letters were anonymised for purposes of analysis, and given the opportunity to decline use of quotations from letters about their application in reports of the project. One applicant declined.

\section{Analysis}

As reported elsewhere, ${ }^{8}$ the RECs' decisions about the outcomes of the applications were consistent between RECs for eleven applications and showed disagreement for seven. In this paper we report the kinds of issues raised by the RECs about the applications. Two forms of analysis were undertaken. First, content analysis, a systematic method for assigning text to content categories, ${ }^{9}$ was used. This allows a consistent and transparent examination of categories that can be expressed in terms of frequencies. We used seven categories based on official guidance given to RECs in the UK (GAfREC). ${ }^{1}$ An eighth "outside-GAfREC" category was added to classify issues that appeared to be outside the remit of GAfREC.

A second distinct and more detailed analysis of issues was enabled through development of a coding scheme based on the principles of ethnographic content analysis (ECA). ${ }^{10} 11$ Defined as the "reflexive analysis of documents", it is this reflexive feature of ECA that makes the approach "ethnographic". ${ }^{10} \mathrm{ECA}$ involves constant and recursive movement between data collection, data analysis through interpretation, and concept development, to generate analytic constructs. Our ECA scheme was produced by all authors 
through close inspection and comparison across the texts of the letters. Explicit specifications for major organising categories and for sub-categories were devised. Coding using both the GAfREC and the ECA schemes was undertaken by EA and CJJ, facilitated by use of QSR N6 software, and was independently checked by MDW. Some quotations used to illustrate the analysis have had identifying details removed or modified to preserve anonymity.

The frequency with which RECs raised issues under the eight GAfREC categories varied across applications and across categories (Table 1). The ECA analysis identified further variability in the nature of the ethical issues that were raised and in the remedies suggested. Where helpful, we therefore report the frequency of issues identified in letters in relation to the number of applications where the issue was raised.

\section{Results}

\section{Informed consent}

Issues relating to informed consent formed the ethical concern most often raised (51 of 54 letters relating to all 18 applications). "Informed consent" was raised by REC1 in 17 letters, REC2 in 18 letters and REC3 in 16 letters. The frequency with which RECs raised specific sub-categories of issues under this broad category varied (Table 2), as did the number of committees raising a given subcategory of this issue for the same application (Table 3). Even where two or more RECs identified the same category of issue, they did not always cite the same specific instance of that issue. In application 4 (a drug trial), for example, "informed consent" was raised by all three RECs, but in relation to different types of concern. For this application, only REC1 identified that participants should be informed that participating in the research might involve additional surgical procedures, only REC2 identified that clarity was needed over whether participants could take oral contraceptives, and only REC3 identified that participants should be advised that although the study drug was licensed, it was being used in unlicensed form in the trial.

Sixteen letters about 10 applications raised concerns about whether the patient information leaflets (PILs) were sufficiently easy to read and understand - though the same concerns were not raised in the other 14 letters about the these same applications. Five letters (of a total of 12 regarding four applications) identified problems of layout, grammar, and font size. 
Please re-write in language understandable to a lay person (application 3, REC2).

Concerns that full disclosure be made to potential participants were prominent. The risk of potential participants being misled about various aspects of the research was identified in 13 letters, though not in the other 14 letters about the same nine applications.

The PIL is non-standard and constitutes more of a letter of invitation rather than providing the participants with detailed information about the project. It was also felt to be somewhat promotional of the product rather than providing a balanced view (application 9, REC2).

Ten letters raised the issue of proceeding without obtaining consent (either generally or in particular circumstances), though the other five letters about the same applications did not. Five of these letters either rejected or questioned plans not to obtain consent.

\section{Scientific design and conduct}

Concerns related to scientific design and conduct were raised in 42 letters relating to all 18 applications, though 12 letters did not raise concerns. The concerns were raised in 13 letters from REC1, 15 letters from REC2 and 14 letters from REC3. The frequency with which committees raised specific matters relating to scientific design and conduct varied. For instance, issues relating to "choice of methods" were raised in four letters by REC1, eight letters by REC2 and five letters by REC3. The number of committees raising a given issue varied for the same applications. For example, although "choice of methods" was raised in 17 letters in relation to 11 applications, it was raised by all three RECs unanimously for only two applications. Even when RECs identified the same issue, the particular questions they raised about this issue often varied. For example, for application 12, one REC expressed confusion about the purpose of the proposed focus group; a second queried whether interviews might elicit better quality data; the third requested further information.

Sampling issues were raised in 21 letters though not in the 15 other letters about the same 12 applications. Concerns about the size of the sample were raised in seven of the 18 letters about six applications. The most common sampling "trouble" related to inclusion and exclusion criteria. This was 
raised in 16 letters, but not in the 17 other letters about the same 11 applications. Fifteen letters highlighted issues concerning quantitative analysis, including appropriateness of proposed statistical analysis, though not the other 15 letters relating to the same 10 applications.

The committee asks if your aims are too ambitious? You plan to examine 27 variables to 0.05 statistical significance in just 30 people (application 1, REC2).

Letters identified concerns about the feasibility of the studies proposed. Such concerns included the likelihood of meeting the objectives using the proposed design or within the specified timescales. Six letters raised queries related to the use or content of questionnaires, including lack of validation, though these issues were not raised in the other nine letters about the same five applications.

One of the child PILs states that other children will be doing the questionnaire, yet A10 states that the questionnaire is validated in adults only (application 11, REC2).

\section{Care and protection of research participants}

The third most common set of concerns, raised in 37 letters relating to 13 applications, were about "care

and protection of research participants". These were raised in 13 letters by REC1, 11 letters by REC2 and 13 letters by REC3, but the frequency with which they raised specific issues varied. For instance, the risk of those involved in research being prevailed upon to do things they might prefer not to do was raised in eight letters by REC1, two letters by REC2, and five letters by REC3. The number of committees raising a given issue varied for the same application. For instance, although the risk of people being "prevailed upon" was raised in 15 letters in relation to 10 applications, there was only one application for which all three RECs raised this issue unanimously. When RECs did raise an issue, they did not always raise it in the same way. This is illustrated in application 16, where two RECs were concerned about travel expenses and the other was concerned that participants might be taking part in another trial. Only one REC raised an issue related to "threat of physical harm", and only one REC raised an issue related to "vulnerable groups" in relation to this application. 
Various types of risk were identified in letters. Emotional risks such as anxiety, distress, and embarrassment were highlighted in 22 letters relating to 13 applications, though not the 17 other letters about the same applications.

Please make it clear what mechanisms are in place should distress be caused by the interview (application 5, REC2).

Fifteen letters relating to 10 applications referred to the possibility of participants being asked to take on potentially unreasonable burdens such as travel expenses or having additional procedures. However, 15 letters about the same 10 applications did not raise these concerns.

Reimbursement for repeated visits to the hospital is not unreasonable for additional visits for the 20 patients. The committee request that you make provision for reimbursement for extra visits (application 16, $R E C 2)$.

The risk of physical harm to participants was identified in 10 letters about five applications. Such risks included harms that might result from drugs, alternative/additional procedures, and from interventions including denial or delay of treatment during "wash-out" periods. However, five letters about the same applications did not raise these concerns.

Please clarify the rates of adverse events with these higher doses of [named drug]. In addition, the committee asks why you will be using this higher dose? (application 4, REC1).

RECs identified particular groups of people as being especially deserving of protection, including people with mental health problems, people unable to read English, healthcare professionals, children, women, members of ethnic minority groups, people with learning disabilities, and terminally ill people.

\section{Protection of research participants' confidentiality}

Confidentiality was raised in 34 letters relating to 14 applications, though not in the other eight letters about the same applications. REC1, REC2 and REC3 raised issues related to confidentiality in 14, 9 and 11 letters respectively. The frequency with which they raised specific issues varied. For instance, issues relating to storage of data were raised in six letters by REC1, but in only three letters from REC2 and 
REC3 respectively. Although storage of data is identified as an ethical trouble in 12 letters relating to eight applications, it was only once identified by all three committees in relation to the same application. The specific issues raised also varied. For example, for application 1, one REC suggested not using a consent form in order to protect confidentiality; a second suggested two options (either telling participants that their data would be accessible to some staff, or not asking for participants' names at all); and the third that participants be informed that data would be accessible to the investigator and the supervisor.

For four applications, six letters identified the need to inform potential participants of the need to break confidentiality under certain circumstances, such as child protection. The remaining six letters about these applications did not identify this need. Concerns about how far anonymity could be assured were raised in 16 letters (of a total of 24 ) relating to eight applications.

In light of the small numbers, the committee was concerned about the anonymity of the comments made by participants [...] it was felt that certain comments may be easily attributable to individuals (application 10, REC1).

\section{Recruitment of research participants}

Twenty-six letters relating to 16 applications raised issues relating to the recruitment of research participants, though this means that these issues were not raised in the 22 other letters about the same applications. REC1 raised these issues in eight letters, REC2 in eight, and REC3 in 10. The frequency with which they raised specific issues varied. For instance, the possibility of coercion was raised in eight letters from REC1 and REC2 respectively, and in 10 letters from REC3. The number of committees raising a given issue varied for the same application. For 15 applications, the possibility of coercion was raised in 26 letters but it was not raised in the 19 other letters about the same applications. There were only two applications where all three RECs were consistent in raising the issue of coercion. Even when the same issue was raised, it was often done in a different way. For example, for application 9, REC1 was concerned with honesty about the nature of the research whereas REC2 was troubled that the information was biased in favour of the product; REC3 did not express concerns about this issue.

This project constitutes commercial validation of a new device. Please be upfront about this both in the application and on the PIL. (REC1) 
The most common concerns in this area referred to the means by which initial contact and recruitment would be conducted.

It is noted that the [intervention] group are consented by an opt-in procedure. However, although the control group have been informed of details of the trial up to two weeks before [...], details have not been provided to ensure that there is no element of pressure to conform (application 16, REC3).

How the participants were to be recruited and who was to obtain their consent was raised by nine letters about seven applications though not by 12 other letters about the same applications.

The Committee felt that a client who does not wish to take part in the study is placed in an invidious situation because of their relationship with the case manager, and may find it difficult to opt out (application 1, REC3).

\section{Community considerations}

"Community considerations" were raised in only two letters; one where researchers were advised to be careful in their reporting (because of anonymity considerations) and another where a REC suggested that the study offered an opportunity for personal development for staff.

\section{Other issues}

Twenty-four letters relating to 13 applications raised issues that could not be coded to any of the GAfREC categories. The potential for the research to affect negatively people other than the research participants was noted in 13 letters, though not in the 17 other letters about the same 10 applications. Risks to other healthcare professionals were identified in some letters, as were concerns about staff acquiring additional burdens.

the [...] team [...] will be taking on an additional body of work, and even though they have consented to take part it is still an additional risk and inconvenience (application 7, REC3). 
The possibility of the research affecting other patients, unborn children, or others not directly involved in the research were also mentioned. Risks to researchers, including the possibility of harassment, were identified in four letters relating to three applications.

Issues relating to problems with documentation were raised in 18 letters relating to 10 applications, including errors such as missing documentation, conflicting information between different documents, or evidently 'wrong' information. However, these issues were not raised in the other 12 letters about the same applications.

Although Question A40 states that computers will be used, this is not confirmed in Question 39. Please revise the form as necessary (application 4, REC3).

\section{Remedies to ethical troubles}

Our analysis identified 83 instances where committees proposed "remedies" to ethical trouble in the 54 letters in the sample (Table 4). No application escaped without a request for an amendment, but the RECs varied in the frequency with which they requested different types of amendment between applications and between RECs. For example, amendments to the patient information leaflet (PIL) were requested in relation to all but one application. However, there were only six applications where all three RECs requested such amendments; for the remainder, remedies to the PIL were suggested by one or two committees only. Even where two or more committees identified the same category of issue, they did not always recommend the same remedy. For example, in relation to application 8 (concerning a comparison of two surgical techniques), issues relating to informed consent were identified by two committees, but the proposals for the resolution of these varied. REC1 made six recommendations for amendment of the PIL, including advising participants of the likelihood that one treatment might be better than the other, and explaining the likely differences in benefit. REC2 made two recommendations for amendment of the PIL, and suggested that participants should be advised that the risks of each procedure were low, but that the study would allow them to be compared. REC3 raised no issues relating to the PIL. 


\section{Discussion}

This project has identified the ethical troubles raised by RECs during the course of their normal work over a year in response to applications from researchers for ethical approval for various study types. Though a necessarily small sample given the difficulties of conducting systematic comparisons in this area, this analysis suggests that issues relating to informed consent were the most common type of ethical trouble identified by RECs, followed by scientific design and conduct, care and protection of research participants, confidentiality, recruitment, and community considerations. There is evidence of variability in the ethical troubles identified by RECs as well as in the ethical remedies recommended to researchers. These findings raise important questions about the role and functioning of RECs in the ethical conduct of research.

First, this analysis suggests that RECs institutionalise some ethical principles as fundamental to sound research practice. The prominence of informed consent as an ethical concern may in part be traced to the institutionalisation of consent as an ethical orthodoxy within bioethical and policy discourses. ${ }^{12}$ Importantly, however, the regulatory role of consent as an "auditable moment" with its own documentation and visibility to judicial scrutiny ${ }^{13}$ is likely to explain some of this focus. On the other hand, some issues - such as "community considerations" were identified as ethical troubles only rarely, possibly reflecting an orientation that prioritises individual safety and choice over public welfare, or that it is easier to think in terms of effects on individuals than on a more vaguely conceptualised "community". Also noteworthy is the frequency with which issues of scientific design and study quality were raised. Though this is one of the categories of GAfREC for which RECs have a remit, the role of RECs in relation to issues of scientific design and quality is increasingly contentious, with the recent Ad Hoc Advisory Group on Research Ethics Committees arguing that RECs should focus on substantive ethical issues rather than scientific ones. ${ }^{14}$ Clearly, there are tensions between various policy stances on this question, but our finding that scientific issues are prominent in RECs' considerations may reflect the ways in which the territory of ethical concern appears to have expanded, ${ }^{12}$ or that distinctions between what is "ethical" and what is "scientific" may be seen as unstable by RECs.

Second, this analysis offers systematic confirmation of previous suggestions of variability in the types of ethical troubles identified by RECs, the nature of those troubles and their remedies. Such inconsistencies have traditionally been treated primarily as evidence of the incompetent, vexatious, or capricious nature of 
the process, ${ }^{15}{ }^{16}$ but our data raise important questions both about how far consistency is achievable or desirable, and about the role of moral authorities in the governance and regulation of research practice.

One way of characterising inconsistency between RECs is to deem it evidence of poor performance. However, any approach to improving consistency that relies on guidelines, increased training or sharing of information - in effect, a more "managed" process - faces many challenges. Evidence in other areas demonstrates the often modest impact of such strategies in effecting change. ${ }^{17}$ This is likely to be even more limited in group-based situations such as RECs, where customs, traditions, styles of working, group dynamics and cumulative and collective knowledge experiences are all likely to influence debates, process and outcome. ${ }^{18}$ Variability in the expertise brought to committees by members is also likely to affect the decisions of RECs; for example, a REC that includes a specialist in neurology might reach an opinion about an application for a trial of an intervention for chronic pain that differs from one that includes a psychologist. Such differences may occur not simply because of differing clinical expertise, but also because of differing scientific knowledge and potentially different views of the moral issues in such research. Furthermore, removing flexibility in the application of rules could result in forms of bureaucratisation where formalistic aspects of decision-making are valued over substantive ones. ${ }^{19}$

Beyond the arguments from organisational theory about the functionality and dysfunctionalities associated with imposing more managed, rule-based systems, a more fundamental challenge to consistency concerns the nature of the work that RECs must do: make judgements about moral matters. ${ }^{20}$ Guidelines in this area are unlikely to function as algorithmic processes, but more as frames of reference. They might provide useful direction and help to reduce inconsistencies between committees that are due to carelessness or inattentiveness to aspects of applications. However, variability in moral judgements is inevitable because it is not simply a matter of reading the moral rules and applying them to applications; discretion is involved when different types of concerns must be weighed up. In the absence of a final moral authority in determining the reasonableness or otherwise of RECs' decisions, it is likely to be impossible to specify what should have been the "correct" response to any particular application.

If there is no single "right" answer to ethical issues in health-related research, can the role of the REC be defended? One important argument is that relying on researchers to have been well trained in ethical practice and to have good consciences, and thus leaving them to self-regulate, exposes the entire 
research community, as well as research participants, to risk. The institution and process of RECs thus serve key functions: discouraging unethical research (including that which never reaches committees), providing a public warrant of ethical probity for researchers, and enhancing sensitivity to ethical issues in research. Researchers may therefore need to accept some inconsistency in decision-making in return for these benefits, in the same way as they accept that the decisions of other gatekeepers of research and its outputs - those of funders and editors, for example - may also appear inconsistent and provocative.

This is not to say that RECs may do and say as they please; their judgements should function with a notion of there being an answer that all reasonable people could accept, and RECs have responsibilities to pursue this in good faith. Although the exercise of judgement may be inherently fallible, it is not merely arbitrary power and caprice; in this respect it is analogous to judicial decision-making. RECs need to be reflexive ${ }^{21}$ and responsible in their decision-making, and satisfactory and effective appeal mechanisms are clearly necessary. But researchers may also need to accept that inconsistency is not necessarily the same as irrationality or illogicality. 


\section{Funding}

East Midlands NHS Innovation Hub funded the analysis (but had no involvement in the decision to submit this paper). COREC gave permission for coordination of the project to be undertaken during working hours. Leicestershire, Northamptonshire and Rutland Strategic Health Authority allowed EA two days for writing up.

\section{Acknowledgements}

Thanks to the members of the three RECs who participated in the study and to the applicants whose applications were used in the project. The idea for this project was conceived following discussions between EA and two REC members (Dr Douglas Tincello and Dr Carl Edwards), and the data collection strategy was designed by EA and Dr Ron Hsu.

\section{Ethics approval}

Support was sought and obtained from COREC in summer 2003. COREC confirmed that the project constituted service evaluation and therefore need not be reviewed by a Research Ethics Committee.

\section{Competing interests}

RA is a member GTAC is the Gene Therapy Advisory Committee, which is recognized for Clinical Trial Regulations purposes as the REC for gene therapy. EA was the administrator of RECs in the strategic health authority where the project was conducted during the period of the project. EA, RA, and MDW currently hold a grant from COREC to conduct a separate analysis of RECs' letters, but do not believe this constitutes a conflict of interest.

\section{Contributorship}

EA conceived the idea for the study and coordinated the running of the project. All authors were involved in devising the ECA coding scheme. EA and CJJ undertook coding of the data. All authors were involved in interpreting the data and identifying relevant literature. MDW obtained funding for the analysis and led on writing of the paper. All authors contributed to the version submitted and approved its submission. 
Table 1

Number of committees raising each issue for each application

\begin{tabular}{|c|c|c|c|c|c|c|c|c|}
\hline \multirow[b]{2}{*}{ Application } & \multicolumn{8}{|c|}{ GAfREC category } \\
\hline & $\begin{array}{l}\text { Scientific } \\
\text { design and } \\
\text { conduct of the } \\
\text { study }\end{array}$ & $\begin{array}{l}\text { Recruitment of } \\
\text { research } \\
\text { participants }\end{array}$ & $\begin{array}{l}\text { Care and } \\
\text { protection of } \\
\text { research } \\
\text { participants }\end{array}$ & $\begin{array}{l}\text { Participants' } \\
\text { confidentiality }\end{array}$ & $\begin{array}{l}\text { Informed } \\
\text { consent } \\
\text { process }\end{array}$ & $\begin{array}{l}\text { Community } \\
\text { considerations }\end{array}$ & Documentation & $\begin{array}{l}\text { Outside } \\
\text { GAfREC }\end{array}$ \\
\hline 1 & 2 & 1 & 1 & 3 & 3 & 0 & 3 & 1 \\
\hline 2 & 3 & 1 & 2 & 3 & 1 & 0 & 3 & 2 \\
\hline 3 & 2 & 1 & 2 & 1 & 3 & 0 & 1 & 2 \\
\hline 4 & 3 & 1 & 3 & 1 & 3 & 0 & 2 & 1 \\
\hline 5 & 3 & 3 & 0 & 3 & 3 & 0 & 3 & 2 \\
\hline 6 & 2 & 1 & 0 & 3 & 3 & 0 & 0 & 1 \\
\hline 7 & 1 & 1 & 3 & 0 & 3 & 0 & 1 & 2 \\
\hline 8 & 2 & 0 & 3 & 0 & 2 & 0 & 0 & 1 \\
\hline 9 & 1 & 1 & 3 & 1 & 3 & 0 & 2 & 3 \\
\hline 10 & 3 & 2 & 3 & 3 & 3 & 1 & 1 & 1 \\
\hline 11 & 3 & 3 & 3 & 2 & 3 & 0 & 0 & 1 \\
\hline 12 & 3 & 0 & 3 & 3 & 3 & 1 & 1 & 2 \\
\hline 13 & 2 & 3 & 3 & 3 & 3 & 0 & 0 & 0 \\
\hline 14 & 3 & 1 & 3 & 0 & 3 & 0 & 0 & 1 \\
\hline 15 & 2 & 3 & 3 & 3 & 3 & 0 & 0 & 2 \\
\hline 16 & 3 & 2 & 3 & 3 & 3 & 0 & 0 & 1 \\
\hline 17 & 2 & 1 & 0 & 2 & 3 & 0 & 0 & 0 \\
\hline 18 & 1 & 1 & 3 & 0 & 3 & 0 & 1 & 1 \\
\hline Total & 41 & 26 & 41 & 34 & 51 & 2 & 18 & 24 \\
\hline
\end{tabular}


Table 2

Number of letters in which issues relating to "informed consent" were raised by each committee

\begin{tabular}{|c|c|c|c|c|}
\hline & REC1 & REC2 & REC3 & Total \\
\hline Informed consent (all issues) & 17 & 18 & 16 & 51 \\
\hline \multicolumn{5}{|l|}{ Provision of information: } \\
\hline Easy to read and understandable & 7 & 6 & 3 & 16 \\
\hline Layout, grammar, font size & 2 & 2 & 1 & 5 \\
\hline $\begin{array}{l}\text { Alternatives to written information or in languages other } \\
\text { than English }\end{array}$ & 0 & 1 & 1 & 2 \\
\hline Misleading nature of the information & 5 & 4 & 4 & 13 \\
\hline $\begin{array}{l}\text { Who was conducting research and what taking part } \\
\text { would involve }\end{array}$ & 4 & 4 & 3 & 11 \\
\hline Proceeding without obtaining consent & 3 & 4 & 3 & 10 \\
\hline Rejected/questioned process & 1 & 2 & 2 & 5 \\
\hline Consent to specific parts of research & 4 & 2 & 4 & 10 \\
\hline Correct procedures in taking consent & 1 & 3 & 1 & 5 \\
\hline
\end{tabular}


Table 3

Number of committees raising each issue relating to "informed consent" for each application

N.B. Grey shading indicates "consistency": either all three RECs or no RECs raised an issue

\begin{tabular}{|c|c|c|c|c|c|c|c|c|c|}
\hline & \multicolumn{9}{|c|}{ Informed consent } \\
\hline Application & $\begin{array}{l}\text { Easy to read } \\
\text { and } \\
\text { understandable }\end{array}$ & $\begin{array}{l}\text { Layout, } \\
\text { grammar, } \\
\text { font size }\end{array}$ & $\begin{array}{l}\text { Alternatives } \\
\text { to written } \\
\text { information } \\
\text { or in } \\
\text { languages } \\
\text { other than } \\
\text { English }\end{array}$ & $\begin{array}{l}\text { Being } \\
\text { misled }\end{array}$ & $\begin{array}{l}\text { Who was } \\
\text { conducting } \\
\text { research } \\
\text { and what } \\
\text { taking part } \\
\text { would } \\
\text { involve }\end{array}$ & $\begin{array}{l}\text { Proceeding } \\
\text { without } \\
\text { obtaining } \\
\text { consent }\end{array}$ & $\begin{array}{l}\text { Rejected / } \\
\text { questioned } \\
\text { process of } \\
\text { not } \\
\text { obtaining } \\
\text { consent }\end{array}$ & $\begin{array}{l}\text { Consent } \\
\text { to specific } \\
\text { parts of } \\
\text { research }\end{array}$ & $\begin{array}{l}\text { Correct } \\
\text { procedures } \\
\text { in taking } \\
\text { consent }\end{array}$ \\
\hline 1 & 1 & 1 & 0 & 2 & 0 & 0 & 0 & 0 & 0 \\
\hline 2 & 0 & 0 & 0 & 0 & 0 & 0 & 0 & 0 & 0 \\
\hline 3 & 1 & 0 & 0 & 0 & 2 & 0 & 0 & 1 & 0 \\
\hline 4 & 1 & 0 & 0 & 1 & 2 & 0 & 0 & 0 & 0 \\
\hline 5 & 1 & 1 & 0 & 0 & 1 & 0 & 0 & 0 & 0 \\
\hline 6 & 0 & 0 & 0 & 0 & 0 & 3 & 3 & 0 & 0 \\
\hline 7 & 3 & 1 & 1 & 0 & 2 & 2 & 2 & 0 & 0 \\
\hline 8 & 0 & 0 & 0 & 1 & 2 & 0 & 0 & 0 & 0 \\
\hline 9 & 0 & 0 & 0 & 2 & 0 & 0 & 0 & 0 & 2 \\
\hline 10 & 1 & 0 & 0 & 0 & 0 & 0 & 0 & 1 & 0 \\
\hline 11 & 3 & 1 & 1 & 1 & 0 & 1 & 0 & 2 & 1 \\
\hline 12 & 0 & 0 & 0 & 0 & 0 & 0 & 0 & 0 & 0 \\
\hline 13 & 1 & 0 & 0 & 3 & 0 & 0 & 0 & 2 & 0 \\
\hline 14 & 0 & 0 & 0 & 1 & 1 & 0 & 0 & 0 & 0 \\
\hline 15 & 3 & 1 & 0 & 1 & 0 & 0 & 0 & 1 & 1 \\
\hline 16 & 0 & 0 & 0 & 1 & 1 & 0 & 0 & 1 & 1 \\
\hline 17 & 1 & 0 & 0 & 0 & 0 & 2 & 0 & 2 & 0 \\
\hline 18 & 0 & 0 & 0 & 0 & 0 & 2 & 0 & 0 & 0 \\
\hline $\begin{array}{l}\text { Number of } \\
\text { applications } \\
\text { where all } \\
\text { RECs are } \\
\text { consistent }\end{array}$ & 11 & 14 & 16 & 10 & 11 & 13 & 17 & 11 & 14 \\
\hline
\end{tabular}


Table 4

Number of committees raising issues relating to "remedies" for each application

N.B. Grey shading indicates "consistency": either all three RECs or no RECs raised an issue

\begin{tabular}{|c|c|c|c|c|c|}
\hline \multirow[b]{2}{*}{ Application } & \multicolumn{5}{|c|}{ Remedies proposed in letters } \\
\hline & $\begin{array}{l}\text { Amendments } \\
\text { to the PIL }\end{array}$ & $\begin{array}{l}\text { Amendments } \\
\text { to other } \\
\text { documents }\end{array}$ & $\begin{array}{l}\text { Amendments to } \\
\text { consent procedures }\end{array}$ & $\begin{array}{l}\text { Amendments to } \\
\text { recruitment } \\
\text { procedures }\end{array}$ & $\begin{array}{l}\text { other } \\
\text { remedies }\end{array}$ \\
\hline 1 & 3 & 0 & 1 & 1 & 1 \\
\hline 2 & 1 & 1 & 0 & 0 & 1 \\
\hline 3 & 2 & 2 & 0 & 1 & 2 \\
\hline 4 & 3 & 0 & 0 & 0 & 1 \\
\hline 5 & 3 & 2 & 0 & 0 & 2 \\
\hline 6 & 0 & 0 & 0 & 0 & 1 \\
\hline 7 & 3 & 1 & 1 & 0 & 0 \\
\hline 8 & 2 & 1 & 0 & 0 & 0 \\
\hline 9 & 1 & 2 & 0 & 0 & 2 \\
\hline 10 & 3 & 1 & 0 & 0 & 0 \\
\hline 11 & 3 & 3 & 1 & 0 & 1 \\
\hline 12 & 2 & 1 & 1 & 0 & 1 \\
\hline 13 & 1 & 2 & 0 & 1 & 2 \\
\hline 14 & 2 & 1 & 0 & 0 & 1 \\
\hline 15 & 2 & 0 & 2 & 1 & 0 \\
\hline 16 & 1 & 2 & 0 & 1 & 0 \\
\hline 17 & 2 & 2 & 0 & 0 & 0 \\
\hline 18 & 1 & 1 & 0 & 0 & 0 \\
\hline $\begin{array}{l}\text { Number of } \\
\text { applications } \\
\text { where all } \\
\text { RECs are } \\
\text { consistent }\end{array}$ & 7 & 5 & 13 & 13 & 7 \\
\hline
\end{tabular}




\section{References}

1. Governance Arrangements for Research Ethics Committees (GAfREC). Available at: http://www.dh.gov.uk/assetRoot/04/05/86/09/04058609.pdf. Accessed 17 April, 2006.

2. Standard Operating Procedures for Research Ethics Committees. Available at: http://www.corec.org.uk/applicants/help/docs/SOPs.doc. Accessed 16 April 2006, 2006.

3. The European Parliament and the Council of the European Union. Directive 2001/20/EC of the European Parliament and of the council of 4 April 2001 on the approximation of the laws, regulations and administrative provisions of the member states relating to the implementation of good clinical practice in the conduct of clinical trials on medicinal products for human use; 2001.

4. Goodyear-Smith F, Lobb B, Davies G, Nachson I, Seelau S. International variation in ethics committee requirements: comparisons across five Westernised nations. BMC Medical Ethics 2002;3(1):2.

5. Hearnshaw $\mathrm{H}$. Comparison of requirements of research ethics committees in 11 European countries for a non-invasive interventional study. BMJ 2004;328:140-1.

6. Pothier DD, Bredenkamp C-L. A plea for consistency in ethical review. Research Ethics Review 2006;2:109-10.

7. Goffman E. The Presentation of Self in Everyday Life. New York: Doubleday; 1959.

8. Angell E, Sutton A, Windridge K, Dixon-Woods M. Consistency in research ethics committee decision-making: a controlled comparison. JME in press; (accepted February 2006);

9. Holsti OR. Content Analysis for the Social Sciences and Humanities. Reading, Mass.: Addison Wesley; 1969. 
10. Altheide DL. Ethnographic content analysis. In: Lewis Beck MS, Bryman A, Liao TF, editors. The Sage Enclycopaedia of Social Science Research Methods Thousand Oaks, Ca.: Sage; 2004.

11. Altheide DL. Qualitative Media Analysis. Thousand Oaks, Ca.: Sage; 1996.

12. Ashcroft RE. The ethics and governance of medical research: what does regulation have to do with morality?. New Rev Bioeth 2003; 1:41-58.

13. Dixon-Woods M, Williams SJ, Jackson CJ, Akkad A, Kenyon S, Habiba M. Why do women consent to surgery, even when they do not want to? An interactionist and Bourdieusian analysis. Soc Sci Med 2005; 62; 2742-53.

14. Department of Health. Report of the ad hoc advisory group on the operation of NHS research ethics committees. London: Department of Health; 2005.

15. Glasziou P, Chalmers I. Ethics review roulette: what can we learn?. BMJ 2004;;328:121-2.

16. Hotopf M, Wessely S, Noah N. Are ethical committees reliable?. J R Soc Med 1995; 88:31-3.

17. Greenhalgh T, Robert G, Macfarlane F, Bate P, Kyriakidou O. Diffusion of innovations in service organizations: systematic review and recommendations. Milbank Q 2004;82:581-629.

18. Kameda T, Ohtsubo Y, Masanoi T. Centrality in sociocognitive networks and social influence: an illustration in a group decision-making context. J Pers Soc Psychol 1997;73:296309.

19. Edwards SJ, Ashcroft R, Kirchin S. Research ethics committees: differences and moral judgement. Bioethics 2004;18:408-27.

20. Merton RK. Social theory and social structure. New York, Free Press, 1968

21. Schön DA. The Reflective Practitioner : How Professionals Think in Action. Aldershot: Ashgate; 1991. 